Article

\title{
Challenging COVID-19 with Creativity: Supporting Design Space Exploration for Emergency Ventilators
}

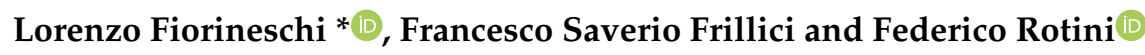 \\ Department of Industrial Engineering, Università degli Studi di Firenze, Via Santa Marta, 3, 50139 Firenze FI, \\ Italy; francescosaverio.frillici@unifi.it (F.S.F.); federico.rotini@unifi.it (F.R.) \\ * Correspondence: lorenzo.fiorineschi@unifi.it; Tel.: +39-055-275-8709
}

Received: 10 June 2020; Accepted: 16 July 2020; Published: 18 July 2020

\begin{abstract}
The high concentration and rapid increase in lung diseases caused by COVID-19 has suddenly led medical staff to face a lack of ventilators in emergency situations. In this context, many enthusiasts and/or designers all over the world have started to think about low cost and open-source solutions for emergency ventilators, with the aim of providing concrete aid. In a small amount of time, many different solutions have been proposed, most of which are based on the automatic compression of the auxiliary manual breathing unit (AMBU) bag. In particular, many different designs have been conceived for the AMBU compression mechanism, which contains the most critical parts to be designed. Here arises the aim of this work, i.e., to propose a methodological approach to support the creativity of designers involved in inventing increasingly sustainable and reliable low-cost compression mechanisms for AMBU-based ventilators. Accordingly, a conceptual framework is proposed, capable of collecting existing ideas and organizing the underpinning concepts, to provide stimuli for new idea generation and to keep track of (and possibly to share) the explored design space. Illustrative examples are provided in order to show how the proposal can be used in practice. In particular, a set of currently available solutions is schematically shown through the proposed graphical tools, and the generation of new illustrative solutions is presented. Additionally, it is shown how to represent further ideas (e.g., those coming from other teams) in the framework.
\end{abstract}

Keywords: COVID-19; conceptual design; creativity; engineering design; ventilators

\section{Introduction}

\subsection{The COVID-19 Pandemic and the Role of Low-Cost Ventilators}

The Coronavirus disease, officially acknowledged as COVID-19 by the World Health Organization (WHO) [1], suddenly led the world to face a critical emergency, with a lot of patients with severe respiratory problems. After the cases in China, Italy was the first occidental country to report a very high number of infections, with a very high concentration in the Lombardy region. The rapid and vast spreading of the infection is sadly acknowledged by everyone, therefore for the scope of this paper it is sufficient to report that currently, more than ten million cases and nearly 500 thousand deaths have been registered throughout the world (data from the WHO website [2]). It has emerged that for supporting the respiration of patients affected by the most severe symptoms, the use of automatic ventilators has been one of the crucial parameters for reducing death cases [3,4]. Unfortunately, and especially in Italy, it rapidly became evident that the available ventilators were outnumbered by the number of patients. Many solutions have been conceived to better exploit the available devices. For example, some studies have focused on the possibility of using the same ventilator for multiple patients (e.g., [5-7]), while others have concentrated on the optimization of ventilator triage procedures (e.g., [8,9]) or the possibility to share ventilators among hospitals [10]. A comprehensive review of 
the different studies concerning ventilators falls out of the scope of this work, where the attention is focused on a particular phenomenon. More specifically, many designers, research groups, or simply enthusiasts have started to provide many open-source contributions of ideas about how to design and manufacture low-cost ventilators or parts of them (e.g., [11-13]), with the aim of supporting the supply of these devices. However, notwithstanding the different attempts to solve the problem, the need for ventilators is still crucial [14]. Therefore, this design-related way to fight the pandemic can also be very helpful because it strives to produce low-cost ventilators that can be easily afforded by hospitals (especially in developing countries, e.g., in Africa or South America). The ventilator design task is quite complex, and, even if focusing on low-cost devices, it is possible to find many problems that need to be faced. Indeed, ventilators can be both invasive and non-invasive [15], and many functionalities need to be carefully considered, from the filtration of the exhaled air to the different controls and requirements that should be satisfied [16].

However, among the different open-source contributions that can be currently found (a list has been recently made [17]), many of them exploit the advantages provided by the adoption of the standard auxiliary manual breathing unit, or simply "AMBU bag" (see Figure 1), which is also known as a bag valve mask (BVM) unit or "manual resuscitator". Notably, the considered type of non-invasive ventilator works by automatically compressing the bag with a mechanical system, hence it overcomes the need to employ a human resource. In cases of emergency, AMBU-based devices can be used to take care of patients when other ventilation systems are not available.

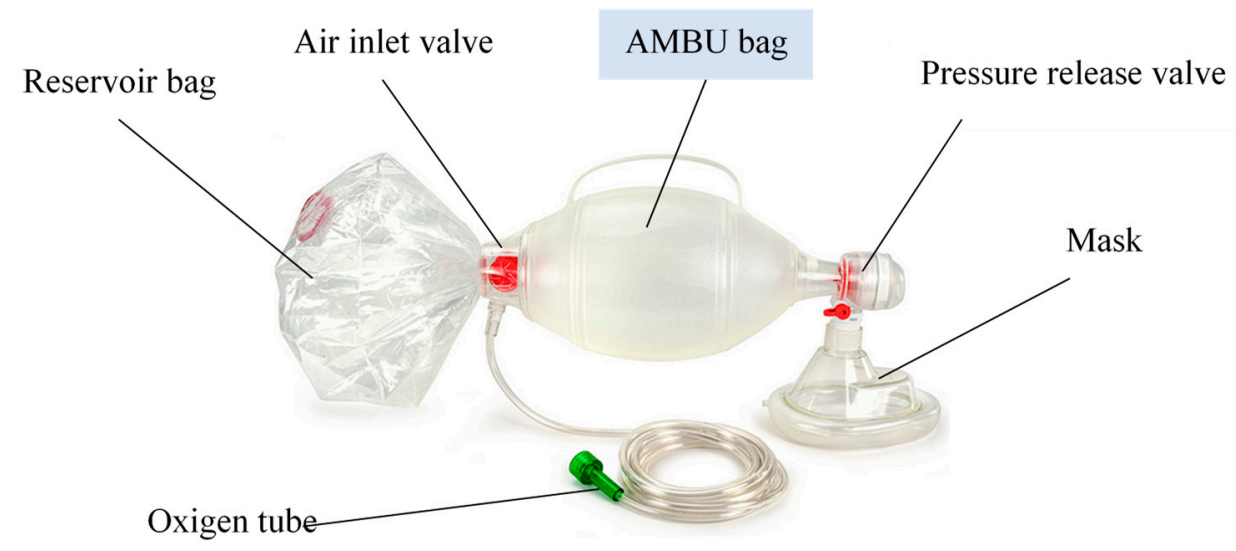

Figure 1. Standard auxiliary manual breathing unit (AMBU) bag and main accessories. The AMBU bag was originally intended to be manually compressed for emergency purposes.

With the aim of providing emergency and non-invasive ventilation systems, AMBU bags offer the opportunity to use parts already available, which are certified according to the standards in force, thus allowing the design efforts to be limited to the mechanism that automatically compresses the bag (and related controls). Moreover, this type of ventilator can be used for both endotracheal tube and non-invasive mechanical ventilation through a mask (similarly to what happens for continuous positive airway pressure (CPAP) ventilation) [18]. It is important to state from the outset that the selection of the most suitable ventilation system is the total responsibility of the medical staff. Medical considerations about the ventilators are not made in this work, which is focused on the conceptual stage of the engineering design process.

The interest of designers, enthusiasts, and users towards this kind of ventilator has grown considerably in the last few months, all over the world. Consequently, several design efforts have been spent to conceive versatile, simple and low-cost devices to compress the AMBU (e.g., [17]).

In such a context, this work focuses on BVM-based ventilators, and aims to propose a methodological approach to support the creativity of designers, i.e., to support them in conceiving new ideas for ventilators. To the best of the authors' knowledge, this is the very first attempt to provide a methodological support for creativity for the design of ventilators. 


\subsection{Creativity in Engineering Design}

Research groups and/or designers involved in the design of the mentioned low-cost ventilators have followed their own design rationale and methodology and indeed obtained very interesting results. Their proposals could be considered creative under certain aspects, but it is important to preface this with the acknowledgment that the concept of creativity is far from being standardized. Accordingly, many definitions of the term creativity can be found in the literature $[19,20]$. However, although it is widely accepted that novelty of ideas is a key concept of creativity [21-24], the case of ventilators further highlights the importance of other parameters like the usefulness and feasibility of the conceived ideas [25-27].

The cognitive mechanisms behind creativity are extremely complex and still a debated topic, but it is widely acknowledged that design fixation (the counterproductive and often involuntary adherence to specific solutions or rationales) [28-31] is one of the main obstacles that hinder the generation of novel and original ideas. The literature offers many hints for overcoming design fixation, or in general for supporting creativity (e.g., [32-34]), where the type of representation of creative stimuli often plays a key role [35-37]. Indeed, it has been observed that providing examples could somehow support creativity, but the form in which such examples are provided may influence design outcomes [35]. Moreover, it has been acknowledged that the abstraction level at which ideas can be represented and differentiated sensibly influences the degrees of novelty and variety of the generated solutions [21,22,38,39]. Additionally, problem-solving and/or design methods claimed to support creativity are available in the literature (e.g., [40-45]). Nonetheless, design methods are often considered difficult to learn by industrial practitioners [46-48], who usually prefer to follow classical "solution-based" or "trial-and-error" approaches. One of the main reasons behind this skepticism is the need to comprehensively understand the rationale underpinning the method. More specifically, if the fundamental rules are not followed and/or the considered terminology is not well understood, the design methods cannot bring the expected support [40].

Therefore, in order to exploit the benefits of a design method, it is crucial that the underpinning rationale (notwithstanding theoretical robustness) is easily understood. This is the key factor that has been taken into consideration for the development of the methodological proposal described in this paper.

\subsection{Objective of the Work: Supporting Creative Conceptual Design of Low-Cost Ventilators}

In line with the opinion of Yoram Reich (who raised the question of how design can help in challenging the coronavirus) [49], and in light of what has been stated in the paragraphs above, at this point a question arises:

- Is it possible to exploit the suggestions from the design science literature together with experience from the already available open-source ventilators, in order to support designers during the conceptual design of new, improved, and low-cost ventilators?

Here arises the objective of the work, i.e., to answer this question by providing an original methodological approach that allows the support of the generation of new ideas, and to keep track of the performed design space exploration.

The main difficulty characterizing the development of such a proposal is the need to balance the requirement of theoretical robustness (in order to exploit the advice from design science) with the need for an easy-to-use tool (in order to rapidly allow its use by any designer anywhere in the world, without any particular knowledge of design theories and methods).

As a result, a structured framework is presented in Section 2, where the co-evolutions of problems and solutions are mapped in a specific network, and a chart is used for representing alternative solutions from the lowest to the highest abstraction level. Theoretical robustness is ensured by considering an original combination of methodological tools, each of them already discussed in authoritative journals. Therefore, theoretical demonstrations of the actual efficiency of the proposal are omitted here, where the 
emphasis is placed on examples and instructions for how to use the proposed approach in practice. Accordingly, Section 3 reports illustrative examples to show how to use the proposal for supporting idea generation at different abstraction levels. Indeed, it is worth highlighting that this paper does not aim to propose any specific new ventilator solution. As we have already said, this paper provides a methodological proposal that can be used by designers in order to collect, organize, and share existing knowledge about solutions and support design space explorations.

\section{Materials and Methods}

\subsection{A Simplified Methodological Framework to Support Conceptual Design}

It can be difficult to select design tools and methods from the literature because there are many available alternatives, each with its pros and cons. Indeed, one can argue that well-acknowledged design textbooks should be taken as a reference (e.g., [40,50-54]), but when talking about how to support creativity, it is impossible to select a widely acknowledged "best" method. For example, although the German systematic design approach is widely taught and acknowledged [55], some non-negligible questions have been raised about its actual capability to support creativity in the conceptual design phase $[56,57]$. Therefore, the selection performed in this work is based only on the authors' experience, by considering the tools and methods that they believed to be the most suited for the main purpose of the work, i.e., to support creativity in the method but with limited need of practice.

More specifically, we hypothesized a framework capable of modeling existing solutions according to different levels of abstraction, in order to represent them by focusing not only on the structural details but also on the working principles. This is a key feature to avoid bias among the designers that will consult them. Indeed, complete information about the available open-source ventilators can be found, in terms of the electrical scheme, detailed CAD models, videos, and photos. However, many of them share the same working principles and differ only in terms of manufacturing-related choices and/or forms. On the other hand, other solutions implement completely different principles, but are sometimes implemented at a very rough level. It is acknowledged in the literature that the way in which a prototype is presented (also called the "fidelity" level) can actually influence the opinion of the audience (in this case, of the stakeholders involved in the development of new ventilators) [58-60]. Therefore, poorly implemented original ideas often risk being discarded because they are "not convincing", if compared to other (maybe older) ideas developed in greater detail.

In order to avoid this problem, we chose to model the compressing unit of the ventilators in two ways, i.e., abstractly with schemas, and graphically with generalized CAD models. For the abstract schematization, we chose to apply the problem-solution network (PSN) approach [61]. In particular, we took its most recent version, where different abstraction levels are considered to formulate both design problems and solutions [44], as a reference. Then, a chart to collect the generalized CAD models of key mechanisms was used, and directly linked to the PSN. The following paragraphs explain both the PSN and the chart.

This particular set of graphical tools allows the representation of ventilators by decomposing them into the main design problems and the related solutions used to implement them. As well as the generation of brand-new solutions for each problem, the proposal allows us to explore different combinations of already explored solutions (not to be interpreted as a mere recombination of parts from acknowledged ventilators).

\subsubsection{Problem-Solution Network}

According to the objective of the present work, the PSN modeling of ventilators has been limited here only to the main functional problem, i.e., that of compressing the AMBU bag. A generic example of the PSN is shown in Figure 2, which is aimed at rapidly showing the main graphical parts characterizing the tool. Indeed, as mentioned in Section 1.2, in order to comprehensively exploit the claimed benefits, it is crucial to learn the underpinning logic and definitions before the practical application of the method. 
The design problems characterizing the system to be modeled (the compression unit in this paper) are represented by yellow boxes, while the related solutions are in the green boxes. Problems are expressed in the form of "How to verb noun?", and can be considered as the inputs of Boolean "AND" ports. This means that if during the conceptual design activity a designer proposes a solution at a certain level (e.g., Solution 1.2), the related sub-problems must be solved in order to consider it suitable for the subsequent design phases. For example, if Solution 1.2.1.1 in Figure 2 were not present, Problem 1.2.1 would remain unsolved, and then Solution 1.2 could not be considered. On the other hand, the solutions can be considered Boolean "OR" ports. Indeed, if a problem presents multiple solutions, any of them as well as any combination of solutions can be considered suitable for the subsequent design phases (according to the design requirements). For more detailed explanations of these fundamental PSN rules, please see [44,61].

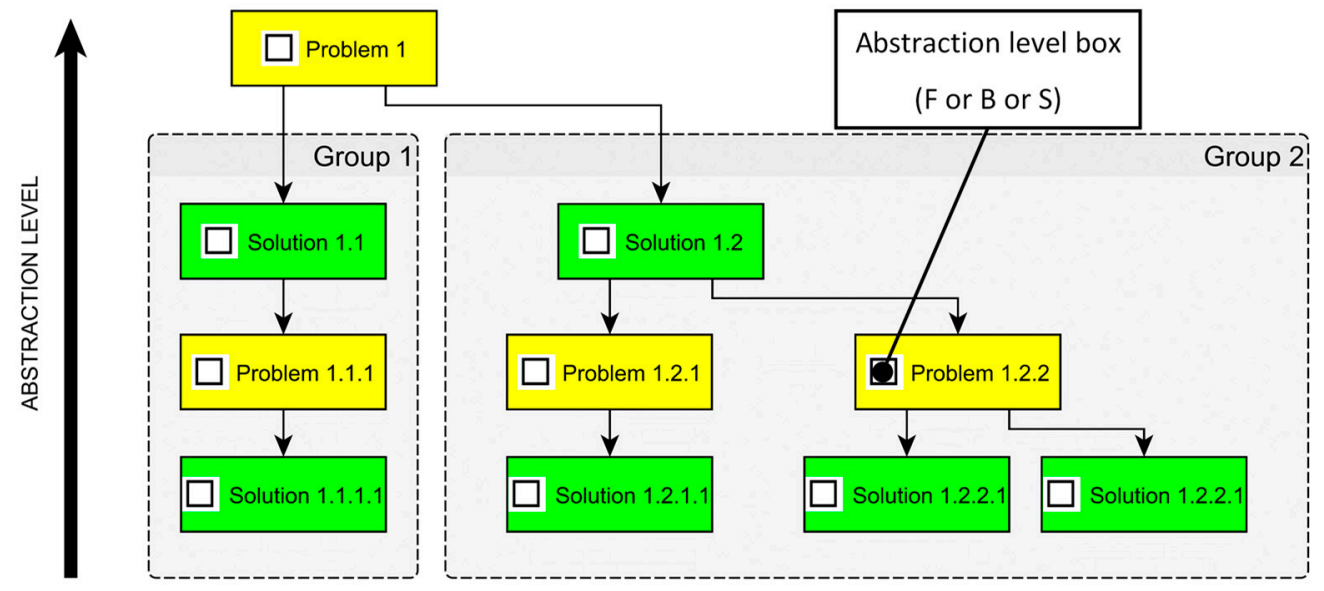

Figure 2. Generic example of the problem-solution network (PSN) used for modeling the AMBU-based open-source ventilators.

The small empty boxes within each problem and solution box are used to indicate the abstraction level. More specifically, many abstraction frameworks can be used as a reference [62-64], but for the purpose of this work, the simplified version was considered according to the function-behavior structure presented in [44]:

- Function (F): A function is identified by an action performed by the system, which can be expressed according to energy-material-signal formalism from the German systematic design approach [40].

- Behavior (B): This abstraction level concerns physical principles, forces, pressures, and any other non-structural elements required for performing the functions. In other words, the behavior represents the fundamentals of "how" the function is going to be implemented

- Structure (S): The structure abstraction level is identified by physical elements such as the structural components and assemblies required for exploiting the behavior selected for implementing a function.

According to the PSN rules [44], problems can be expressed only at the F and B levels, while solutions can be expressed at all three available levels. Therefore, a letter (F, B, or S) is placed as a tag in the small box within the yellow and green boxes, this highlights the considered abstraction level to which the content of the box refers (see Figure 2). Indeed, a simple rule has been conceived to push designers to think abstractly, thus avoiding premature jumps towards concreteness (and then overcoming design fixation). In practice, the designer is asked to avoid jumps from $F$ problems to $\mathrm{S}$ solutions as much as possible. When it is not possible to avoid the mentioned F-S jump, this is highlighted with a thick red arrow in the PSN. The rule was explained and justified in [44], but can be summed up as follows: "try to formulate PSN boxes at the highest possible levels". However, additional fundamental PSN rules must be considered [44,61]: 
- Green boxes (when present) must follow yellow boxes and vice versa. Subsequent boxes of the same color are not allowed.

- Ramifications are independent of each other. This means that any ramification is developed independently of any other ramification (the independency rule). When information from other PSN branches is needed in order to formulate a problem in another ramification, it means that the latter cannot be further developed.

- Each problem or solution box can be reached by only one arrow.

An additional white box has been introduced in this paper to simplify the representation of the different solution variants that characterize the analyzed ventilators at the lowest level (according to the independency rule), as shown in Figure 3.

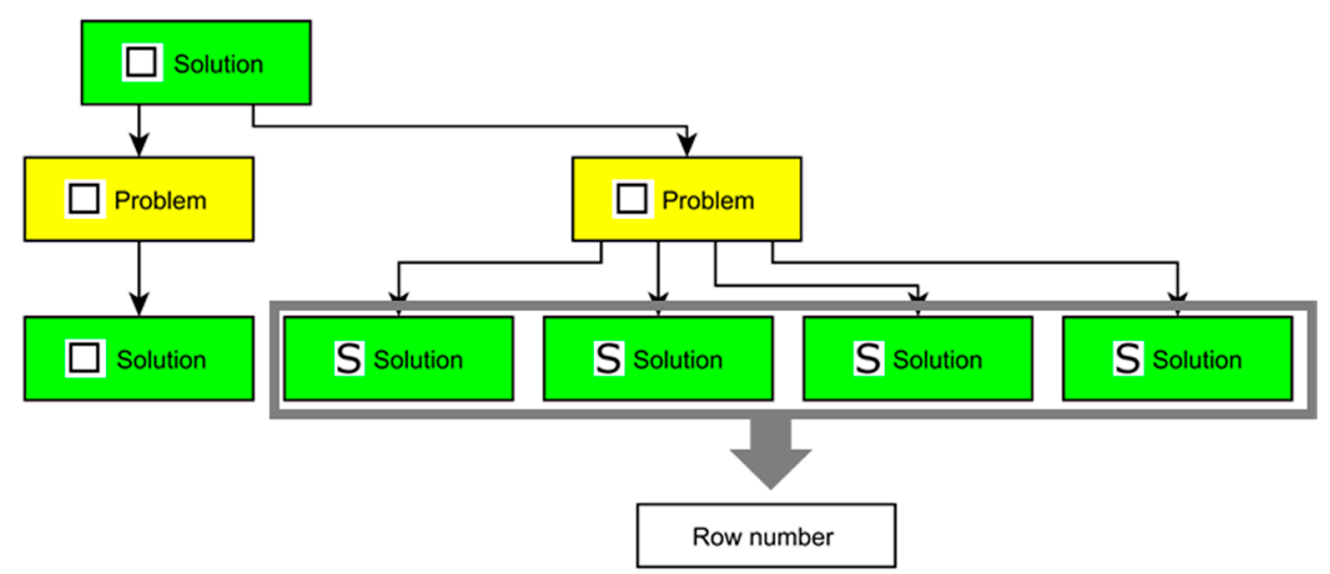

Figure 3. The white box collects all the alternative solutions at the structural level. It indicates the row number of the chart (see Figure 4) where the images of the generalized CAD models of each solution are reported.

\subsubsection{The Chart of Structural Solution Alternatives}

Each white box in the PSN (Figure 3) is a direct link to a specific row of the chart where the images of the generalized CAD models of each solution are reported (Figure 4). The chart appears quite similar to a morphological matrix [40,65], but is different in its nature. Indeed, differently from a morphological chart, not all the rows can be considered but only those coming from the ramifications selected in the PSN. However, with simple computer tools (e.g., Microsoft Excel) it is possible to build the whole chart (i.e., with all the rows), and then apply filters to hide the unnecessary rows. In other words, only the rows from the selected PSN ramification remain visible. The "filtered chart" is then a morphological chart and can be used accordingly, as shown in Figure 5. In particular, in the example shown in Figure 5, a filter has been applied to the generic chart in Figure 4, simulating the selection of rows 1, 3 and n, i.e., the red boxes from the selected ramifications in a hypothetical PSN. Once the filters have been applied and only the selected rows are visualized, the chart allows the consideration of many different combinations of the solutions belonging to the different rows (i.e., alternative solutions to the low-level problems of the PSN). More specifically, the example in Figure 5 shows three different combinations. In other words, this tool allows us to support creativity according to what was stated by Boden [66], i.e., that creative ideas can be obtained by novel and valuable combinations of acknowledged (familiar) ideas.

The selection of the type of representation to be inserted into the rows follows specific criteria. Indeed, it has been demonstrated in the literature that the way in which stimuli (in this case, the representations of the structural solution variants) are represented can affect the creativity of the design outcomes (e.g., [34,35,37]). However, while it seems that there is no difference between sketches and more detailed representations (e.g., photographs and CAD models) in terms of the novelty of the generated ideas, it seems that CAD models allow designers to obtain ideas characterized by 
higher quality [35]. Therefore, in the chart, an image of the 3D CAD model of the structural solution was inserted as a good compromise between a fully accessible 3D model and the need to use a 2D representation. Nevertheless, 3D models are also made available.

\subsection{How to Use the PSN-Chart Framework}

The PSN and the chart are intended to support designers in the early conceptual design phases when performing design space explorations. However, at least three different uses can be discerned:

- $\quad$ Adding new ventilator concepts for subsequent activities.

- Supporting the identification of brand-new solutions.

- Supporting the identification of new combinations of existing solutions.

In the following paragraphs, instructions for each of the mentioned uses are provided.

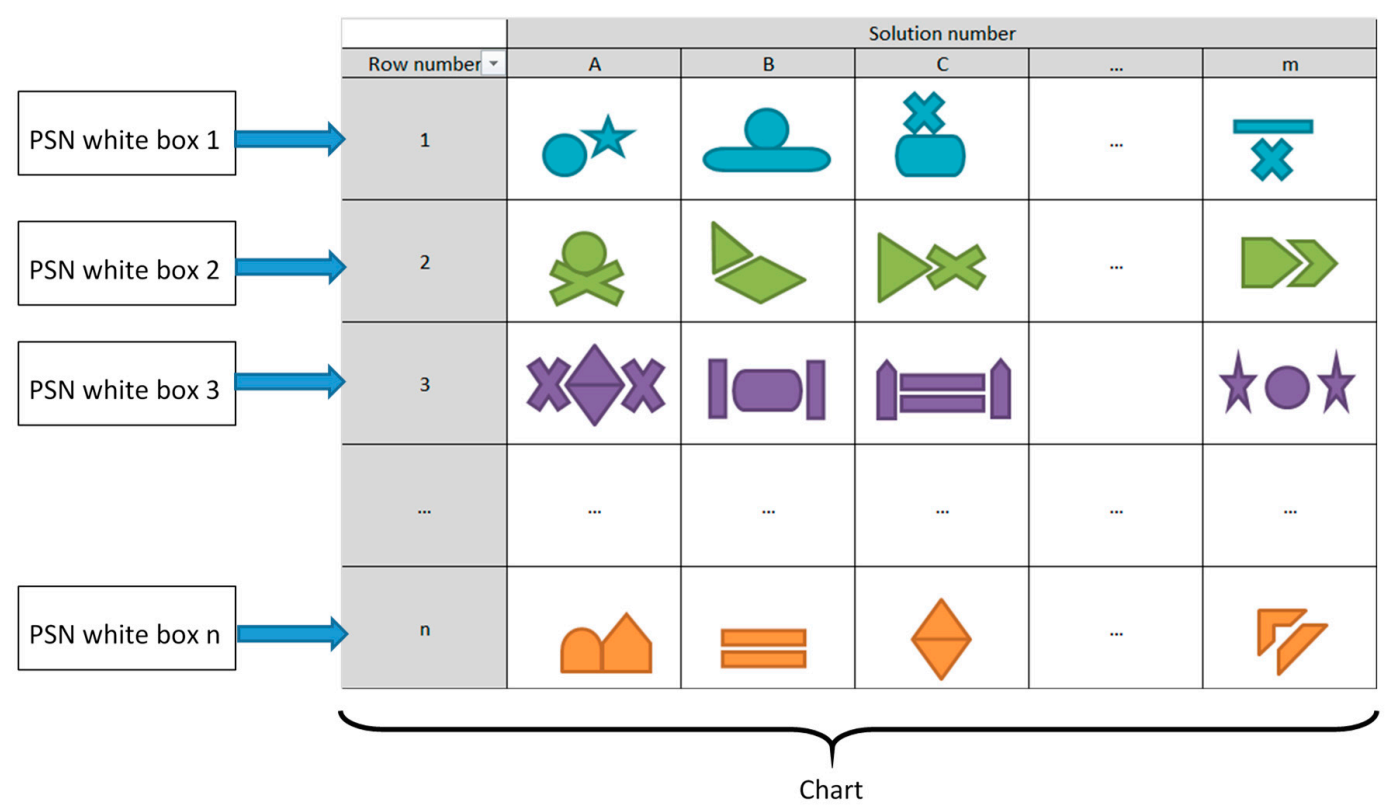

Figure 4. Generic example of a whole chart with all the rows, without filters. It shows all the available solutions in the white boxes for all the PSN ramifications. It cannot be used as a morphological chart.

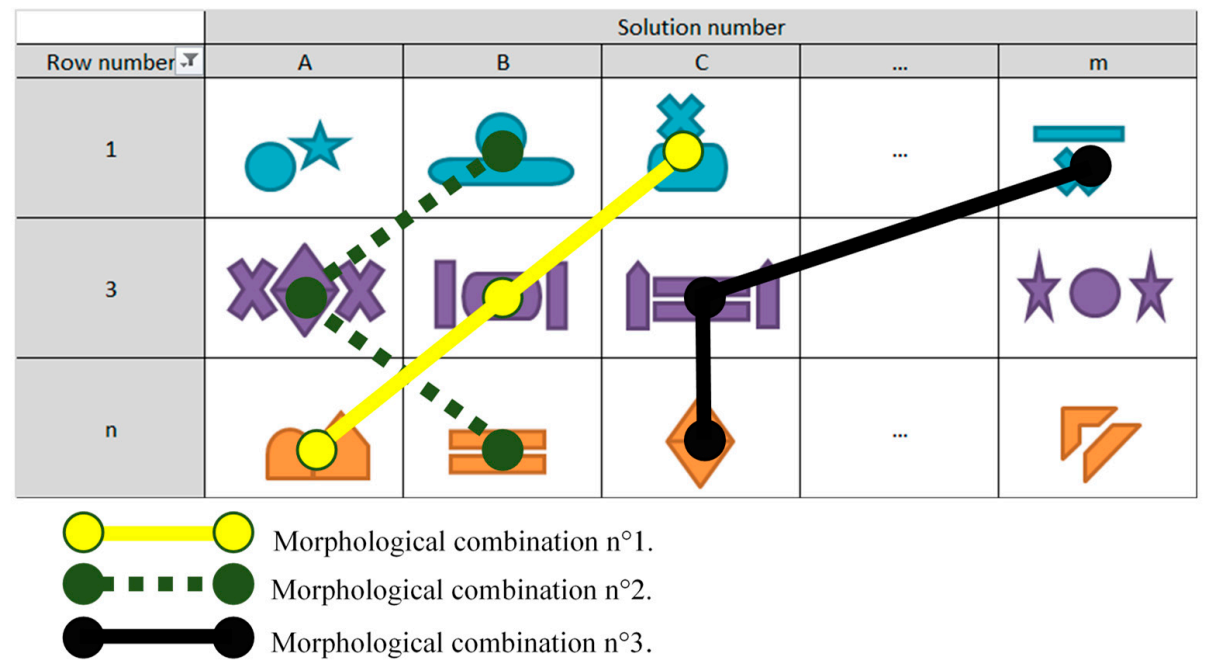

Figure 5. Chart from Figure 4, where filters have been applied (simulating a selection on a hypothetical PSN), and only rows 1, 3 and " $n$ " are active. The filtered chart can now be used as a morphological chart. 


\subsubsection{Adding New Ventilator Concepts}

In order to model the AMBU-based ventilators available in [17], the PSN rules were applied as described in Section 2.1. The obtained results are shown in Section 3, but it is sufficient to anticipate here that the resulting PSN constitutes the starting point for further idea generation activities. To provide a generic example, we consider the PSN shown in Figure 2 and suppose that it is the final network representing the analyzed ventilators. Then, each problem (yellow box) and solution (green box) is extracted from the analyzed ventilators. If other ventilators are identified, the following procedure allows the updating of the network:

- Verify if the required ramifications are already present in the PSN.

- If the PSN ramifications are sufficient to abstractly represent the ventilator, nothing more needs to be done in the network.

- If the PSN ramifications are not sufficient to represent the ventilator, add the required problem-solution sequences, according to the rules described in Section 2.1.

If the designer feels that the new ventilator is also characterized by a structural solution that could be substituted with other possible alternatives, it is possible to add a new white box in the PSN, and then to add the related new row on the chart. Obviously, if the white box is assigned for the first time, the new row will be initially populated by only one solution. However, it provides the starting point for the generation of new structural solutions belonging to that specific PSN ramification.

This procedure is fundamental to allow the abstract representation of the compression units, and to comprehensively discern differences at different abstraction levels.

\subsubsection{Supporting the Identification of Brand-New Solutions}

Each PSN problem (yellow box) has at least one solution (green box), which has been extracted from the analyzed ventilators. Nevertheless, each problem represents a potential starting point for new possible design space explorations. Indeed, for each problem new solutions can be added, which can be characterized by additional problems and so forth, thus leading to completely new ramifications and possibly to new white boxes (and then new rows in the chart).

According to many acknowledged creativity and idea generation assessment metrics (e.g., $[21,22,38,39,67-69]$ ), explorations performed at the high abstraction levels used in the PSN offer the opportunity to attain greater novelty and variety. However, other explorations can be performed at the structural level in the rows of the chart. Indeed, the designer can add an indefinite number of solutions in each row.

\subsubsection{Supporting the Identification of New Combinations of Existing Solutions}

After completing the PSN and the chart (or when the designer simply cannot find other solutions), it is possible to explore new combinations of the collected solutions. This can be done both at the abstract levels in the PSN and at the structural level in the chart (as shown in Figure 5).

However, the chart can be used only after the application of the filters, and then only after the selection of specific ramifications in the PSN. Such a selection actually represents the identification of new possible combinations at the high abstract levels. Indeed, by selecting alternative solutions for each problem in each branch, it is possible to obtain different combinations of white boxes, and then to apply different settings of the filter to the chart.

Once the chart has been reduced according to the ramifications selected in the PSN, the designers can try different morphological combinations (see Figure 5) to stimulate the generation of new ideas for the whole ventilator concept (in the same way as the morphological charts of the German functional decomposition and morphology approach $[40,70])$. 


\section{Results}

\subsection{Network and Chart from the Reviewed Ventilator Projects}

The AMBU-based ventilators reviewed in [17] were analyzed in order to extract the main characteristics of the compression mechanism. In particular, according to the proposed framework, the ventilators are represented abstractly by means of the simplified PSN formalism shown in Figure 3. Although some ventilators showed very similar working principles, a quite articulated network was obtained. An overview of the network can be seen in Figure 6. Please note that a full-scale view of the PSN shown in Figure 6 was reported in [71] (open access dataset).

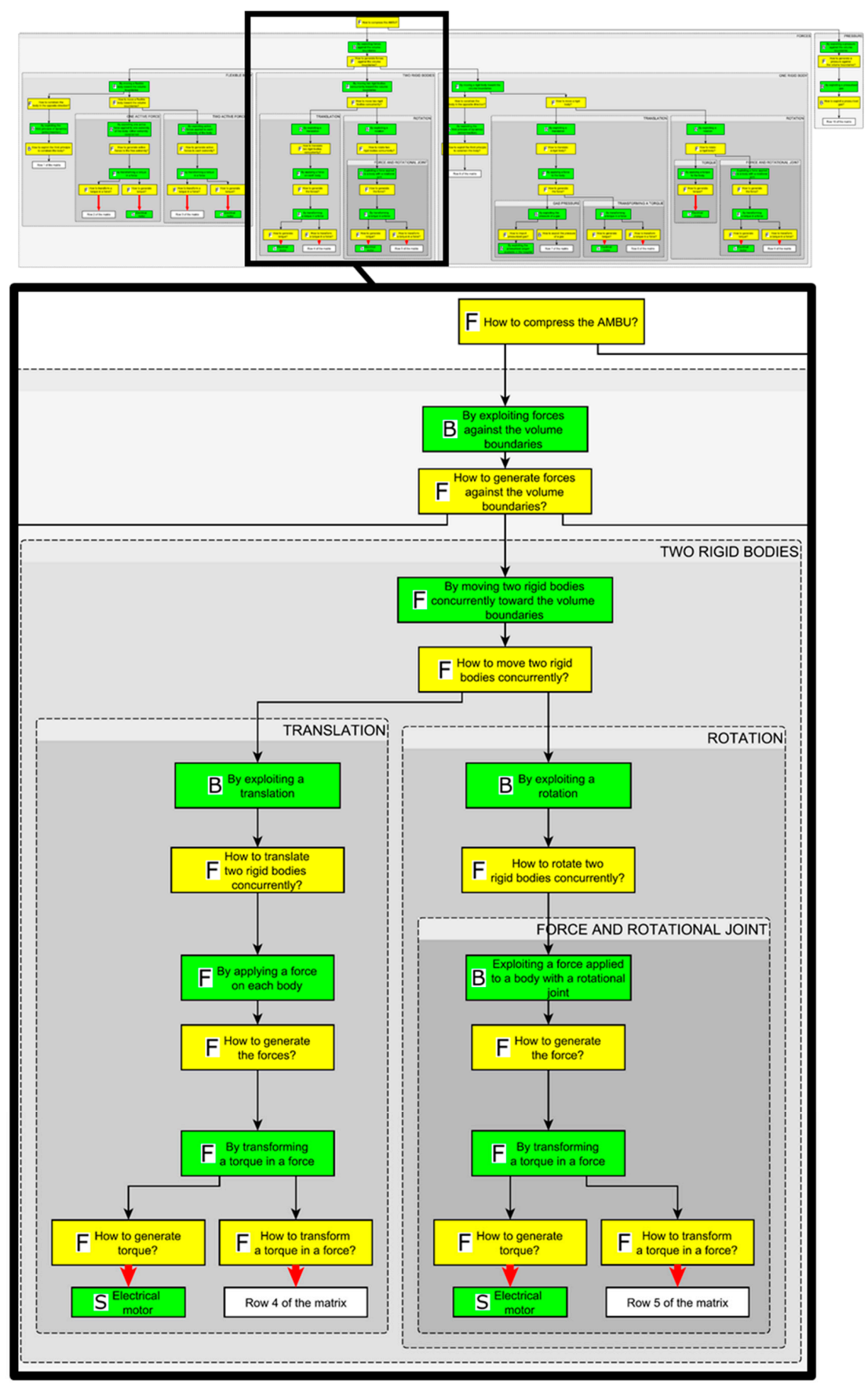

Figure 6. Overview and detailed excerpt of the simplified PSN obtained to represent the ventilators reviewed in [17]. Please see the freely available dataset [71] for a full-scale view. 
The obtained chart shows that although more than forty ventilator concepts were analyzed, some rows are still poorly populated. This means that the designers explored only some PSN branches and the related white boxes (i.e., leading to the specific rows of the chart). Understanding the reasons for such preferences falls out of the scope of this work, but it is possible to infer that the PSN and the chart provide an immediate overview of the solutions, suggesting that many unexplored possibilities exist in the design space. In fact, the preferred mechanisms for compressing the AMBU exploit forces generated by one or two rigid bodies moving against the bag while a few concepts exploit a flexible belt tightened against the AMBU from one or two sides. As mentioned before, only one concept among those reviewed in [17] used external pressure to directly compress the bag (last row of the chart in Figure 7).

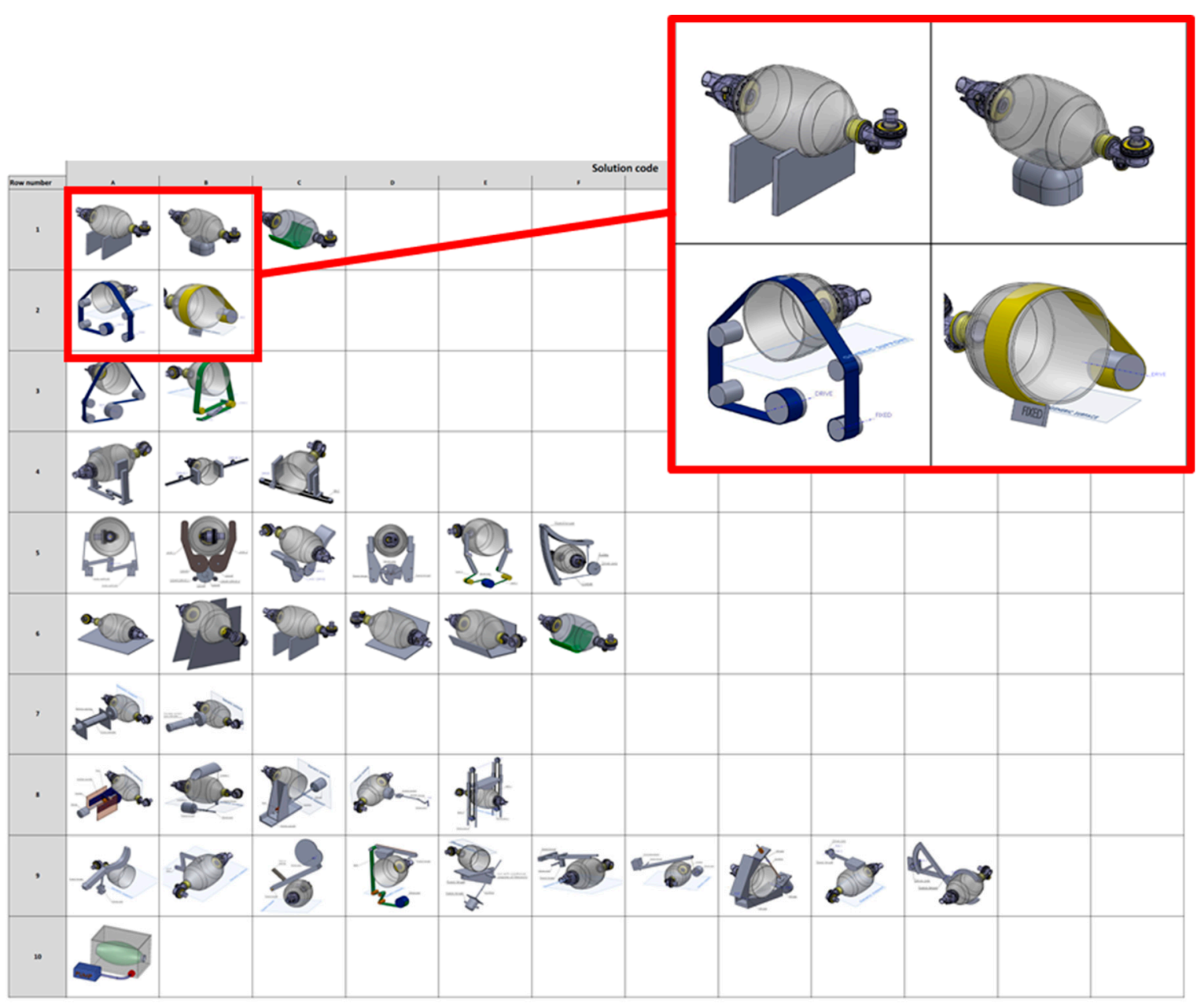

Figure 7. Overview and detailed excerpt of the chart obtained from the PSN shown in Figure 6. Please see the freely available dataset [71] for a full-scale view.

\subsection{Structural Concept Variants from Existing Solutions}

The first and most simple way to exploit the proposed framework is to use it as a design catalogue, where the collected information can be used to generate new overall concepts by taking inspiration from existing solutions. This is what was done by an Italian firm, who exploited the framework to generate a new ventilator concept.

In particular, the solution took inspiration from the PSN branch that considers two bodies moving against the bag, and then from row 4 of the chart shown in Figure 7. More precisely, the PSN branches that inspired the firm are depicted in Figure 8 (the other branches of the PSN have been compressed). 


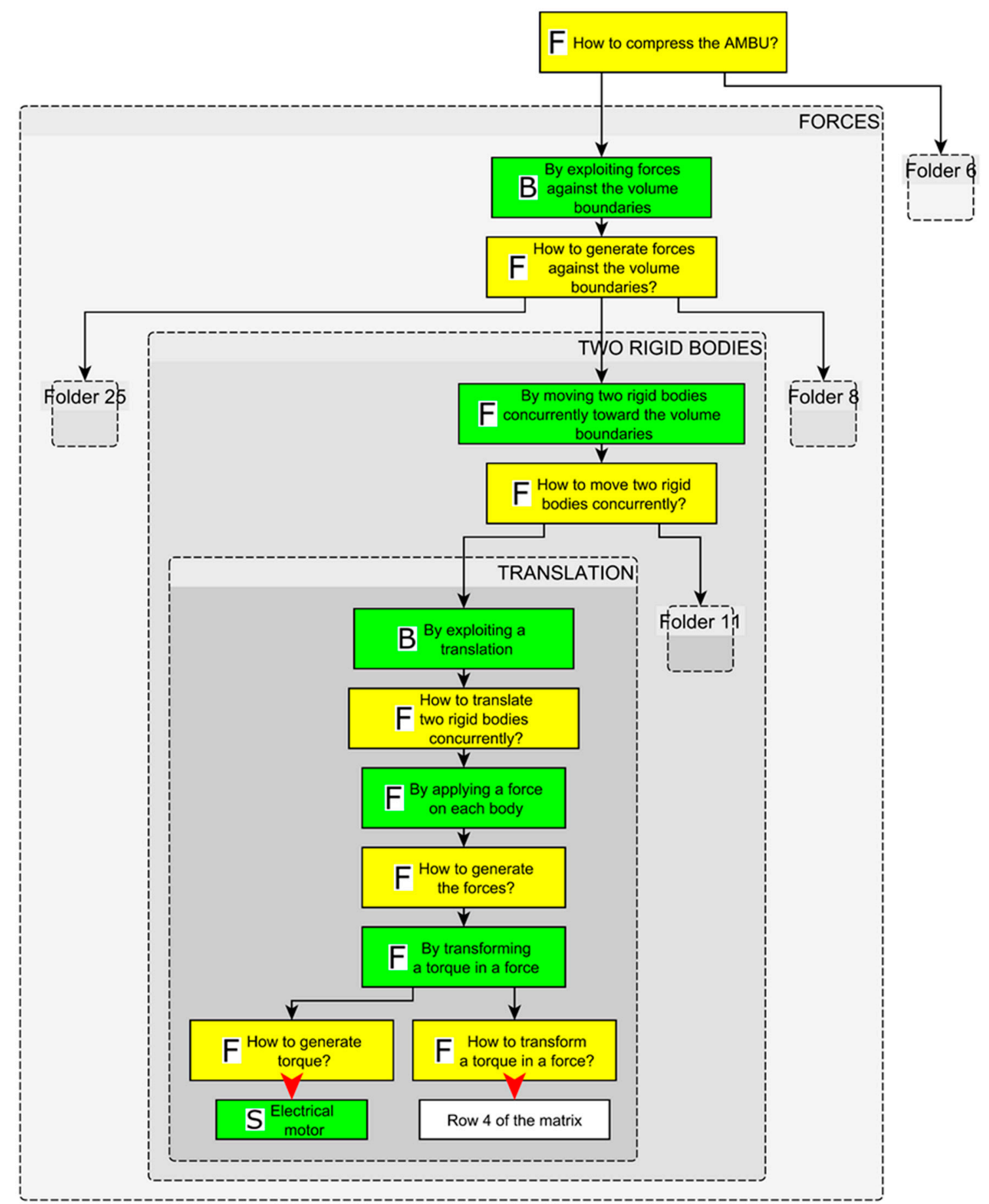

Figure 8. PSN branches that inspired the firm in the design of the new ventilator. For a full-scale view, please see the freely available dataset [71].

Among those present in row 4 of the chart, one specific solution was considered worthy of attention by the firm, because it allowed them to think about a very simple mechanism. In particular, the first solution in row 4 of the chart represents two bodies moved by a gear and two gear racks. The schematic representation used in the chart avoided any particular reference to the construction choices made by the designers of the concepts reviewed in [17]. In this way, the risk of design fixation problems was drastically reduced. Accordingly, the designer was able to slightly modify the initial idea (rotating the gear racks by 90 degrees), and to obtain a new particular version of the solution (Figure 9). Indeed, a central pinion ("drive gear" in Figure 9) moves two gear racks directly connected 
to the bodies that compress the AMBU. Moreover, this particular interpretation of the solution allows designers to exploit the same plastic chassis (e.g., made of Delrin or POM) as a guide for the gear racks.

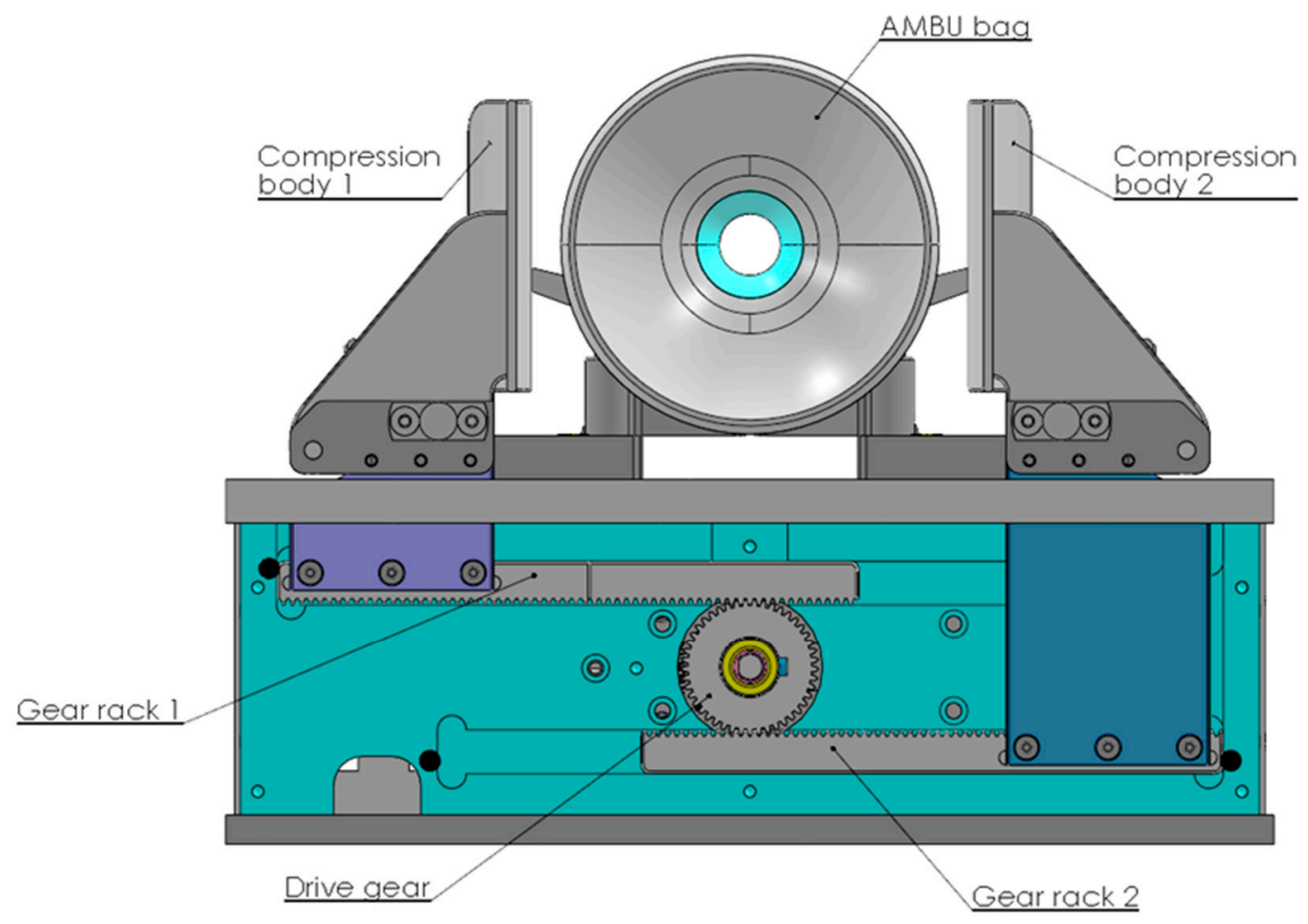

Figure 9. The compression mechanism of the new ventilator concept. It has been derived from the first solution in row 4 of the chart (see [71]).

The motivations that lead designers to get inspiration for a specific solution can be different and difficult to extract. However, by asking the designers about the reasons that led to this specific solution, it emerged that among the different solution paths that could be extracted from the PSN and the chart, this specific one (gear and gear racks) was implementable with elements that were often used by the firm. Additionally, the electronic control of the motor (whose design is not supported by this proposal) with this configuration was very similar to other applications where the internal staff was involved.

A first prototype has been built and used to perform duration tests aimed at identifying the pros and cons of the concept, as well as at identifying failures to be faced in further design iterations. Additionally, it is worth mentioning that the actual ventilation efficiency must be tested with care and in the presence of medical staff in order to verify compliance with the required safety specifications.

\subsection{New Combinations of Existing Solutions}

Another possible use of the proposed framework involves taking inspiration from different combinations of the solutions present in the chart's rows selected through the PSN.

For example, by considering the PSN ramifications that lead to rows 1 and 3 (see [71]), the related filtered chart is that represented in Figure 10. 


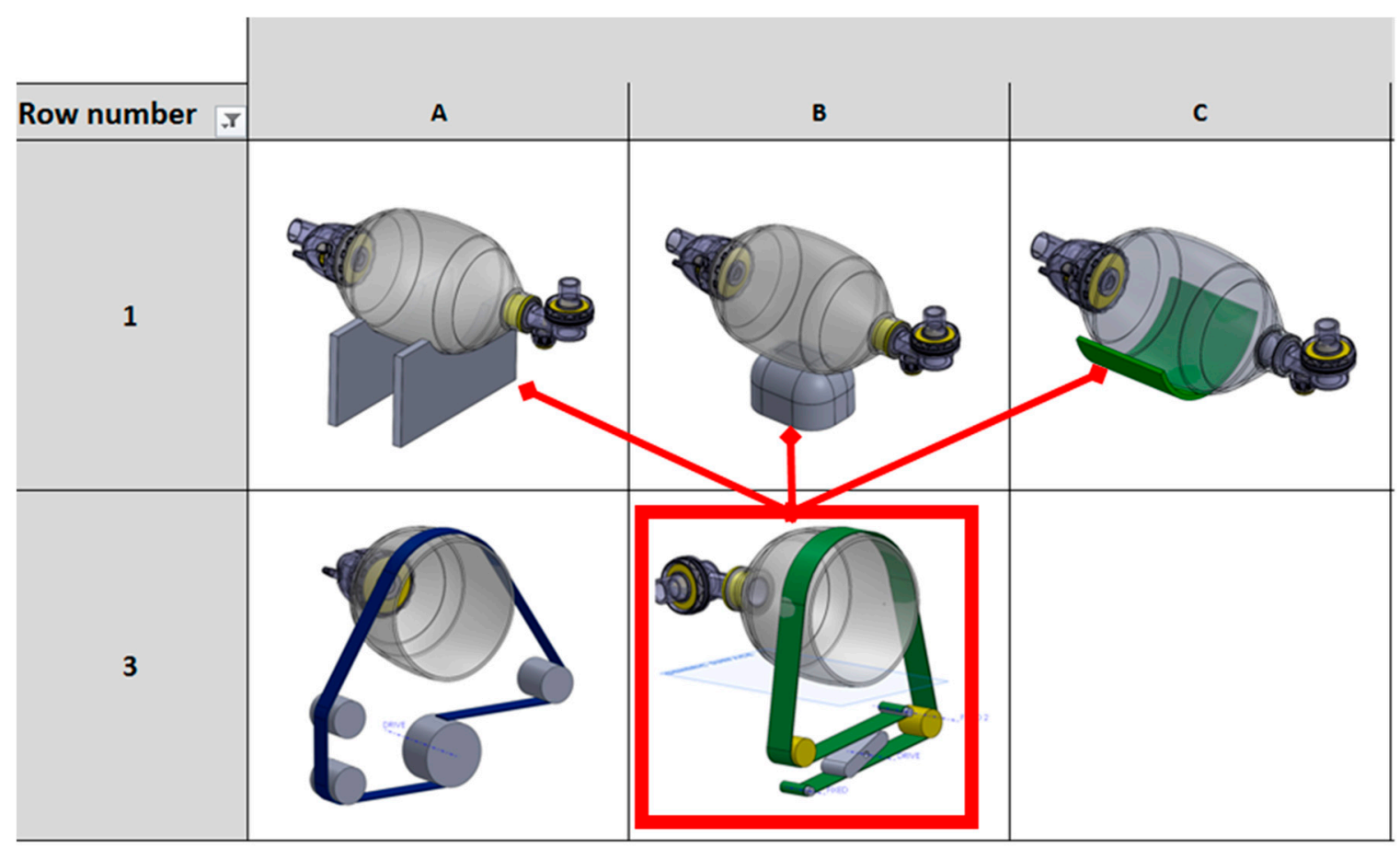

Figure 10. Filtered chart with only the required rows activated. The reference solution for the compression mechanism is that in row 3 and column B. It can be combined with each of the solutions in row 1. For a full-scale view, please see the Microsoft Excel file in the freely available dataset [71].

The solution in row 3 and column B was not developed in detail by the original designers (only a rough sketch was presented), and the required AMBU physical constraint is represented only in a very schematic form (just a generic plane). Therefore, just for illustrative purposes, new hypothetical concepts can be obtained by combining the solution identified by row 3 and column B with each of those present in row 1 (see Figure 10), i.e., the structural solutions adopted by the considered ventilator concepts to constrain the AMBU against the compressing force. It is important to note that this operation is not possible when considering the solutions from the PSN branches (in the simplified version shown in Figure 6) regarding "two bodies" moving against the AMBU. Indeed, at the abstract level considered in this paper, only one row is sufficient to describe the solution.

Therefore, the tool offers the opportunity to perform early design considerations about the new possible concepts that could be derived from the different combinations. For example, it is possible to assert that considering the combination of solutions at row 3 column B with that at row 1 column A, some problems could arise with the AMBU bag. Indeed, while the adoption of two parallel supports allows the easy location of the belt compression system in the middle of them, it is important to consider possible problems due to the bending of the AMBU under the action of the belt. On the other hand, if considering the solution at row 1 column B, more efficient compression is possible, but lateral stabilization of the AMBU bag is required.

\subsection{Keeping Track of New Solutions}

It is quite probable that meanwhile, as well as the concepts considered in this work [17], others have been developed by research teams and/or enthusiasts. As already mentioned in this paper, a comprehensive investigation of the state of the art falls out of the scope of the work, but it is important to show how to use the proposed tools to keep track of new ideas.

The first possible way to do that consists of adding new structural solutions in specific rows of the chart. As explained in Section 2.2.1, the procedure is quite simple and starts by checking whether the available PSN branches are sufficient to describe the new idea abstractly. When this is the case, 
it is possible to identify the specific rows of the chart (white boxes in the PSN), and then to check if there is a schematic representation resembling the new idea. This is quite a subjective procedure, because designers can focus on different levels of generalization. For example, the mechanism shown in Figure 9 has been developed by taking inspiration from the solution in row 4 column A of the chart (see [71]). However, one can argue that the new solution is quite different, because the gear racks and the pinion are oriented in a different way. In this case, it is obvious that the PSN branches are sufficient to abstractly describe the idea (only for the compression mechanism), since it has been inspired by a specific row of the chart, i.e., a specific white box in the simplified PSN. Therefore, it is possible to add a new solution to the chart by inserting a new item representing the particular structure (see Figure 11).

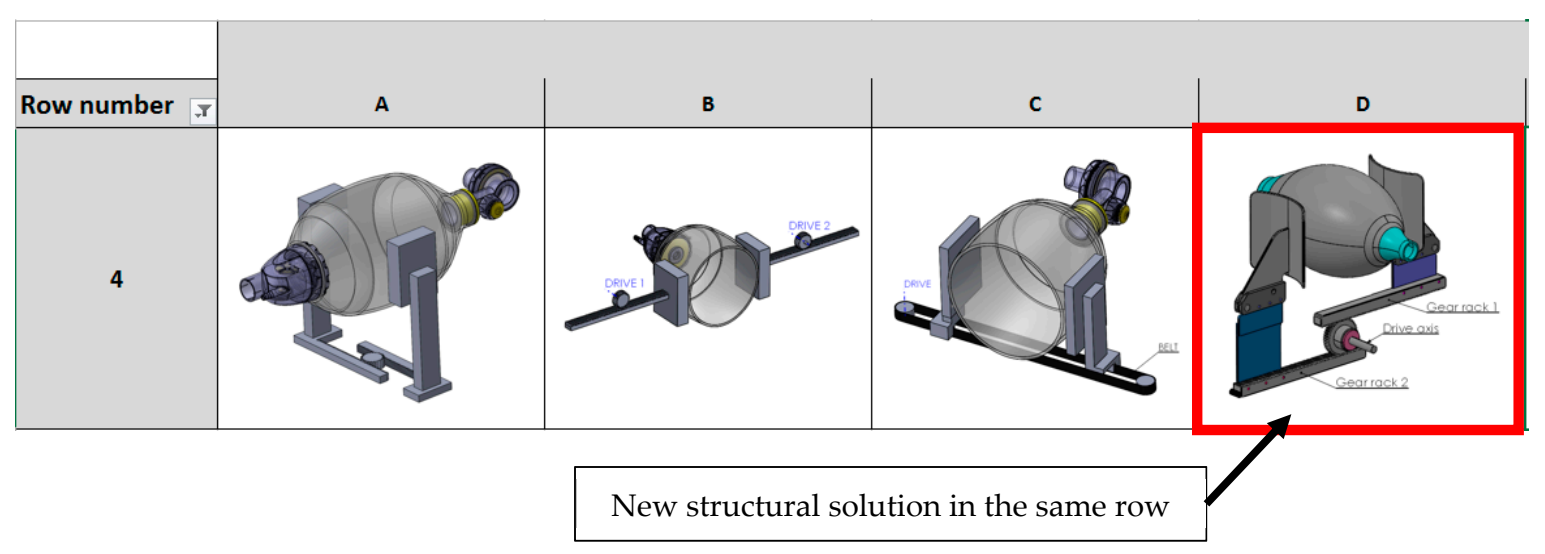

Figure 11. The solution of Figure 9 added to the same row of the chart that inspired the designer (see [71] for the full-size view).

When PSN branches are not sufficient to represent the new concept (i.e., there is not a specific white box and then a row of the chart containing similar ideas), it is necessary to identify the level at which the new branch can be added. For example, considering the "Pressure" branch in the PSN (see Figure 12a and [71]), this allows us to describe solutions that exploit pressurized gases to compress the AMBU, directly in contact with the bag. However, the compressibility of gases can lead to uncertainties and additional difficulties for the control system. Indeed, different gas temperatures and moisture contents can involve different responses from the compression unit, as well as condensation that can cause problems to the pumping system. The use of an incompressible fluid, like a liquid, can certainly avoid these problems and also ensures a stable response from the compression unit. However, this solution cannot be represented by the current branch. Therefore, the additional branch shown in Figure 12b has been added, in order to consider also the use of liquids. Coherently, an additional white box is added and then an additional row in the chart (row 11). Accordingly, these new box and row allow to represent any new ideas that exploit a liquid to directly compress the AMBU bag. Some illustrative examples are provided in Figure 13. In particular, the solution in row 11 column A exploits a piston to move the liquid and then to compress the AMBU. On the other hand, the solution in column B exploits liquid contained in a tank, moved by means of a lobe pump. Both these solutions need a watertight box to contain the AMBU, allowing an easy access to both the input and output pipings of the bag. It is important to highlight that differently from the solutions in rows 1-9, both the presented solutions also allow control of the expansion of the AMBU, thus allowing control of the exhaling of the patient. The solution in row 10 is also theoretically exploitable for this additional function but with all the complications derived from using a compressible fluid (i.e., possible delays in the AMBU movement and/or behavior variations due to different temperature conditions).

The authors conceived the new ideas shown in Figure 13 by exploiting the proposed framework. In particular, the PSN allowed the rapid identification of poorly investigated design spaces, and then focused the attention on them in order to find brand-new ideas. Therefore, it can be considered another example of how to use the framework to support idea generation. 


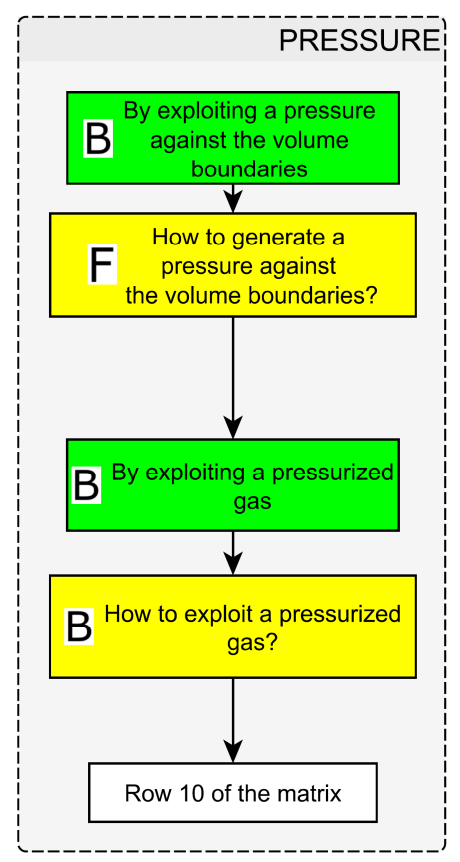

(a)

Current version of the PSN branch

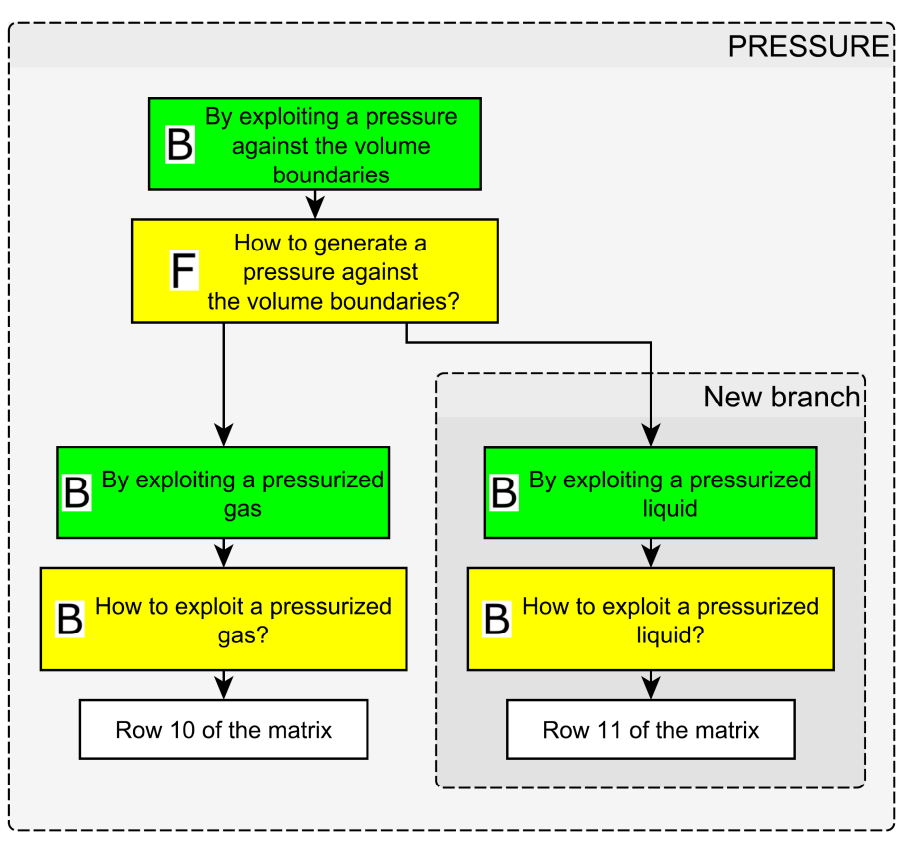

(b)

New solution that implies the addition of a new branch and then a new white box

Figure 12. Illustrative example to show how to add new branches in the PSN, in order to keep track of new ideas that cannot be described in the available rows of the chart (i.e., the available red boxes in the PSN).

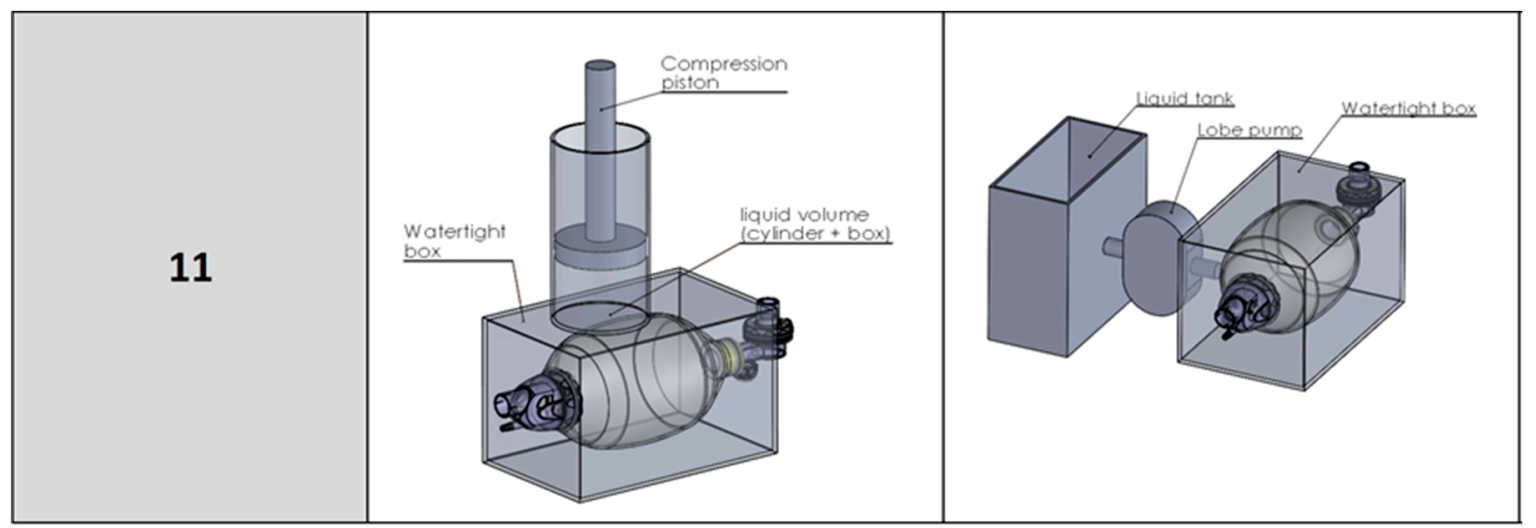

Figure 13. Two hypothetical solutions for the new row added to the chart (row 11), as a consequence of the new PSN branch shown in Figure 12 (see [71] for the full size view).

\section{Discussion}

\subsection{Obtained Results}

\subsubsection{Methodological Proposal}

As mentioned in Section 1.3, the main research question referred to the possibility of exploiting design science and already available open-source ventilators in order to support designers in conceiving new and increasingly better low-cost ventilators. What we presented in this paper did not aim to perform robust tests of the method or to propose a specific new ventilator. On the contrary, priority was assigned to the need to support designers for the purposes of the COVID-19 pandemic. Accordingly, 
the proposed framework provides a new original way to exploit the design tools and methods available in the literature to provide creative stimuli and to keep track of design space explorations and achieved outcomes. The latter characteristic is of fundamental importance, because it means that both the PSN and the chart can be easily upgraded and improved each time by any user, allowing them to add an indefinite number of new ideas. Consequently, in this context of open-source projects and idea sharing, the proposed framework constitutes a valid tool for supporting different teams in organizing and sharing ideas systematically and also using them as a potential source of inspiration for generating other outcomes.

Indeed, it has been shown how both the PSN and the chart can be easily exploited not only as a source of stimuli for conceptual design, but also as a structured framework to archive new ideas in a way that considers different levels of abstraction. Indeed, a further advantage of having a structured base of knowledge about the topic is the ability to minimize the resources spent on retrieving and collecting useful information for supporting the design tasks.

Additionally, both the PSN and the chart available in the dataset [71] can be used by designers as the starting point for their design space explorations, according to the procedure proposed in this work. Then, the proposed framework is intended to support multidisciplinary design tasks where different skills and competences cooperate to find solutions starting at the early conceptual design phases. This is acknowledged to be crucial for product success, because if designers start from a poor concept, it is extremely difficult to obtain optimal results [52]. Indeed, the so-called sunk cost effect [72] can additionally actually hinder the possibility of abandoning the initial ideas, even if they are affected by obvious problems.

\subsubsection{Additional Results}

The ventilator concept shown in Figure 9 is an example of how the framework can support early conceptual design thinking for the generation of new ideas. However, it also allows us to show how to use the chart for archiving the new solution. Besides the mere illustrative purpose, such ventilator is actually a new and almost ready-to-use solution for the compression unit. Accordingly, it represents another solution that can be added to the considered review [17].

Other brand-new hypothetical ideas have been generated by the authors (see Figures 12 and 13) to illustrate how to use the framework in a generative way (see Section 3.4). In particular, these new ideas are very different from the others considered in this work, because they potentially allow the active support of patients' exhalation by the direct control of AMBU expansion. However, any consideration of the actual utility and feasibility of these new ideas is out of the scope of the paper. Scholars and/or designers interested in these specific ideas must perform comprehensive investigations into their advantageous and disadvantageous features.

Indeed, this paper aims at supporting early conceptual design processes focused on the main mechanical components of the compression unit. However, different choices in terms of mechanical solutions may have different impacts on the design of the related control systems. For example, concepts based on the solution at row 8 column $\mathrm{E}$ (the rod-crank mechanism) are surely very simple from a merely mechanical point of view. However, the particular mechanism makes it difficult to control different speeds for the compression and expansion movements, which are both within a single rotation of the drive axis. On the other hand, solutions such as that shown in Figure 9 allow the easy discernment of the forward and backward movements.

\subsection{Limitations and Future Developments}

Many limitations can be ascribed to this work. First of all, the performances of the proposed framework in terms of creativity enhancement have not been measured, but only examples have been provided. Although this could be seen as a non-negligible limitation, hindering any comprehensive and scientific validation of the proposed approach and tools, it is worth highlighting that the main purpose of the work was to provide a practical approach to support designers in challenging the 
COVID-19 pandemic by generating new ideas for ventilators. Accordingly, the proposal actually provides an original way to exploit morphological matrices and the PSN.

Nevertheless, also from a design science point of view, it can be considered an interesting result, but the actual performance of the proposal needs to be investigated with scientifically sound procedures. For that purpose, well-acknowledged metrics and approaches can be exploited for designing specific experiments and assessing the design outcomes in terms of creativity (e.g., [21,22,68,73,74]). Additionally, in order to better understand how the framework actually stimulates designers, experimental procedures based on the analysis of design protocols $[75,76]$ should be followed in future studies.

Concerning the considered ventilators, the paper is focused only on the AMBU-based concepts reviewed in [17], without checking for the presence of other ideas. However, it is worth noting that the paper aims at providing the fundamentals and the instructions needed to apply the proposal. The PSN and the chart compiled in this paper can be updated and upgraded with new ideas, according to the procedure described in Section 2 and illustrated in Section 3. This constitutes possible guidance for future research activities where the proposed framework can be used to comprehensively collect and review all the available ventilator concepts. To this end, it is important to highlight that as declared at the beginning of this paper, only the main mechanism of the compression unit was considered in this work. However, the PSN and the chart allow users to model the whole ventilator system. The reason that led the authors to avoid a comprehensive modeling of the system was the need to provide an easy and ready-to-use tool. This implies that the possible combinations of solutions from different rows of the chart are quite limited. However, if needed, designers can use the PSN to model additional functional problems of the system, and then to obtain more rows on the chart. Therefore, a possible direction for future work can be the comprehensive modeling of the collected ventilator projects, in order to support design space explorations of the whole system.

Finally, it is important to highlight that the design of a ventilator is quite a complex activity involving different disciplines. This paper only focuses on the mechanical design of the main mechanisms, but for obtaining good results, it is important to perform comprehensive discussions and co-design activities with medical staff and electronic and software engineers. The ideas whose generation is supported by the proposal presented here are intended to promote the mentioned discussions in the early design phases, limiting the negative effect of the sunk cost effect.

Secondary design problems such as the filtration of exhalation, controls, and safety measures (although extremely important) were not considered here. This choice was made in order to ease the understanding of the proposal, but at the same time to allow designers to exploit it for the most impactful part of the system. It is implicitly assumed that for a correct design procedure, designers follow robust design procedures (e.g., [40,52,53]), where a thorough definition of the design task also plays a key role, and in which all the required functions and related requirements are carefully identified $[40,77-80]$. Accordingly, the proposed framework is intended to be used for early conceptual design phases.

\subsection{Expected Impact}

\subsubsection{For the COVID-19 Pandemic}

It is surely pretentious to assert that a methodological contribution relating to design methods can directly save lives, but new ideas can potentially have this effect. However, cognitive psychologists are still unable to find a comprehensive and shared explanation of what actually can trigger the generation of new ideas. It may depend on the expertise level of the designer, the working environment, the availability of stimuli, and/or simply on her/his innate skills. However, as mentioned in Section 1, the adoption of design methods and tools to support design space exploration can be useful and worthy of consideration, especially for conceptual engineering design tasks. It is impossible to foresee how many new and feasible ideas can actually be generated by the proposed approach. 
Nevertheless, it should be considered an additional resource that actually supports design space exploration, and which can potentially lead to multiple stimuli for idea generation. This is how this work is expected to practically support the challenging of the COVID-19 pandemic, within the context of low-cost ventilators for emergency situations. Indeed, although richer countries may have sufficient resources to acquire more efficient (and costly) ventilation devices, poorly developed countries do not have this possibility. Unfortunately, the infection is still spreading, and it is crucial to provide as many solutions as possible that could help in reducing deaths and/or patients' pain.

\subsubsection{For Design Science}

The proposal presented in this paper is one of the first demonstrations of how years of design science studies and debates about creativity can actually be helpful for real-life problems. In fact, it is the first contribution that proposes a specific design method to support the design of ventilators. Therefore, this paper paves the way for a new type of research aimed at studying and exploiting creativity from a more practical point of view. Nevertheless, comprehensive investigations of its actual support for creativity must be performed with the acknowledged procedures. However, this paper is also expected to highlight a further research question: how the current creativity assessment approaches can identify those pros and cons of design methods that can actually have an impact on real-life applications?

The answer to this question is not trivial. Indeed, many different concepts and definitions of creativity and related parameters can be found in the literature $[66,81,82]$, but it is still not clear which of them should be used to better represent specific real-life applications.

\section{Conclusions}

The work described in this paper aimed at presenting a specific methodological approach to support designers in conceiving new AMBU-based emergency ventilators for challenging the COVID-19 pandemic. In particular, the authors exploited the design science literature and the experience gained from a set of available open-source ventilator projects in order to propose a structured framework for supporting early conceptual design activities. More specifically, the work focused on the main mechanism of the AMBU compression unit projects, thus neglecting detailed considerations of secondary mechanical parts. Similarly, considerations of electronical controls were also neglected. However, this does not imply that the design of ventilators can be performed without considering these features. Instead, the proposed framework is expected to promote discussions among designers from different disciplines from the early conceptual design phases onward. Indeed, the possibility of performing comprehensive discussions in early conceptual design phases is deemed to be very important to overcome the fixation derived from the sunk cost effect.

The proposed framework consists of two main elements, i.e., the PSN and the chart of structural solutions, which are intended to be used by following the specific instructions reported in Section 2 . In particular, the PSN provides an abstract description of the available ventilators in terms of design problems and solutions, expressed at different abstraction levels. This particular representation offers the opportunity to focus attention on the underpinnings of the ventilator ideas, avoiding bias effects derived from the particular structure used to implement them. Then, specific white boxes in the PSN collect the structural solution variants available to solve the design problems expressed at the lowest PSN level. In particular, each white box identifies the specific rows of the chart where simplified CAD representations of the structural solutions are reported.

The proposal is intended to provide creative stimuli for designers, as well as to keep track of design space explorations performed during the conceptual design of ventilators. More precisely, design problems characterizing ventilators can lead to different solutions at different abstraction levels. These solutions actually represent the underpinning of different ventilator concepts, and then allow to the schematic representation of different concepts with a single graphical tool. Some examples were presented in order to better show how to use the proposal. In particular, a ventilator was developed by taking inspiration from one of the solutions collected in the chart. 
The limitations of the work have been comprehensively listed and discussed, both from purely methodological/theoretical and practical points of view. However, it has been shown that these limits are a direct consequence of the priority of this work, i.e., the need to propose an easy-to-use but methodologically sound framework to support designers involved in designing/conceiving new ventilators. Nevertheless, the same limitations pave the way for future research, also from a design science view. Indeed, acknowledged experimental procedures can be directly applied in order to test the proposed approach and to assess its actual effectiveness in supporting creativity.

Concerning the impact of the outcomes, both social and scientific ones have been considered. In particular, it is expected that the presented proposal will provide an effective support for challenging the COVID-19 pandemic, within the context of the mechanical design of low-cost ventilators. In particular, the creative stimuli and the underpinning rationale of the proposed approach offer the opportunity to generate brand-new ideas, as well as original and non-obvious combinations of already explored solutions. Additionally, the methodology constitutes a new proposal that should be carefully examined from a design science point of view. Indeed, the original combination of the PSN and the morphological matrix has been used here for the first time, showing higher potentialities if compared with the separate use of these tools.

Author Contributions: Conceptualization, L.F.; methodology, L.F.; investigation, L.F.; data curation, L.F. and F.S.F.; writing—original draft preparation, L.F. and F.R.; writing-review and editing, L.F., F.S.F., and F.R.; supervision, F.R. All authors have read and agreed to the published version of the manuscript.

Funding: This research received no external funding.

Acknowledgments: The authors acknowledge the efforts made by research teams, designers and enthusiasts all over the world that supported the challenge of the COVID-19 pandemic with their creative ideas. Their work made possible the conceptualization of the work presented in this paper. Among them, the authors thank the firm "STERN Progetti Srl" for their participation and for giving authorization to publish the image of their new ventilator (see Figure 9). Full-size views of the graphical tools proposed in this paper [71].

Conflicts of Interest: The authors declare no conflict of interest.

\section{References}

1. World Healt Organization. Naming the Coronavirus Disease (COVID-19) and the Virus that Causes it. Available online: https:/www.who.int/emergencies/diseases/novel-coronavirus-2019/ technical-guidance/naming-the-coronavirus-disease-(covid-2019)-and-the-virus-that-causes-it\#: \{\}: text=ICTVannounced \T1 \textquotedblleftsevereacute, on11February2020 (accessed on 6 May 2020).

2. World Healt Organization Coronavirus Disease (COVID-19) Pandemic. Available online: https://www.who. int/emergencies/diseases/novel-coronavirus-2019 (accessed on 1 July 2020).

3. Younes, A.B.; Hasan, Z. COVID-19: Modeling, Prediction, and Control. Appl. Sci. 2020, 10, 3666. [CrossRef]

4. Soufi, G.J.; Hekmatnia, A.; Nasrollahzadeh, M.; Shafiei, N.; Sajjadi, M.; Iravani, P.; Fallah, S.; Iravani, S.; Varma, R.S. SARS-CoV-2 (COVID-19): New discoveries and current challenges. Appl. Sci. 2020, $10,3641$. [CrossRef]

5. Chatburn, R.L.; Branson, R.D.; Hatipoglu, U. Multiplex Ventilation: A Simulation-based Study of Ventilating Two Patients with One Ventilator. Respir. Care 2020. [CrossRef] [PubMed]

6. Futier, E.; Jaber, S.; Joannes-Boyau, O. Ventilating multiple patients on a single ventilator: Statement from the French Society of Anaesthesia and Intensive Care Medicine (SFAR). Anaesth. Crit. Care Pain Med. 2020. [CrossRef] [PubMed]

7. Tonetti, T.; Zanella, A.; Pizzilli, G.; Irvin Babcock, C.; Venturi, S.; Nava, S.; Pesenti, A.; Ranieri, V.M. One ventilator for two patients: Feasibility and considerations of a last resort solution in case of equipment shortage. Thorax 2020. [CrossRef] [PubMed] 
8. Matheny Antommaria, A.H.; Gibb, T.S.; McGuire, A.L.; Wolpe, P.R.; Wynia, M.K.; Applewhite, M.K.; Caplan, A.; Diekema, D.S.; Hester, D.M.; Lehmann, L.S.; et al. Ventilator Triage Policies During the COVID-19 Pandemic at U.S. Hospitals Associated With Members of the Association of Bioethics Program Directors. Ann. Intern. Med. 2020. [CrossRef] [PubMed]

9. Reynolds, A.; Brodie, D.; Levine, A. Considerations for ventilator triage during the COVID-19 pandemic. Lancet Respir. 2020, 2600, 30192. [CrossRef]

10. Adelman, D. Thousands of Lives Could Be Saved in the US During the COVID-19 Pandemic If States Exchanged Ventilators. Health Aff. (Millwood) 2020, 39, 1-5. [CrossRef]

11. Lai, B.K.; Erian, J.L.; Pew, S.H.; Eckmann, M.S. Emergency Open-source Three-dimensional Printable Ventilator Circuit Splitter and Flow Regulator during the COVID-19 Pandemic. Anesthesiology 2020, 133, 246-248. [CrossRef]

12. British Dental Association. Project launched to develop ventilator parts and masks. BDJ Pr. 2020, $33,8$. [CrossRef]

13. Dondorp, A.M.; Hayat, M.; Aryal, D.; Beane, A.; Schultz, M.J. Respiratory Support in Novel Coronavirus Disease (COVID-19) Patients, with a Focus on Resource-Limited Settings. Am. J. Trop. Med. Hyg. 2020, 102, 1191-1197. [CrossRef] [PubMed]

14. Wells, C.R.; Fitzpatrick, M.C.; Sah, P.; Shoukat, A.; Pandey, A.; El-Sayed, A.M.; Singer, B.H.; Moghadas, S.M.; Galvani, A.P. Projecting the demand for ventilators at the peak of the COVID-19 outbreak in the USA. Lancet Infect. Dis. 2020, 3099, 19-20. [CrossRef]

15. Benditt, J.O. Full-time noninvasive ventilation: Possible and desirable. Respir. Care 2006, 51, 1005-1012. [PubMed]

16. Cosentini, R.; Aliberti, S.; Brambilla, A.M. ABC Della Ventilazione Meccanica non Invasiva in Urgenza, 2nd ed.; Mc Graw HIll: Milano, Italy, 2010.

17. Read, R.L. Ventilators Verification Project. Available online: https://www.pubinv.org/project/ventilatorverification-project/ (accessed on 6 May 2020).

18. Mohsen Al Husseini, A.; Ju Lee, H.; Negrete, J.; Powelson, S.; Servi, A.; Slocum, A.; Saukkonen, J. MIT E-VENT|Emergency Ventilator Design Toolbox. In Proceedings of the 2010 Design of Medical Devices Conference, Minneapolis, MN, USA, 13-15 April 2010; pp. 1-9.

19. Sarkar, P.; Chakrabarti, A. Studying engineering design creativity-Developing a Common Definition and Associated Measures. In Proceedings of the NSF International Workshop on Studying Design Creativity'08, Aix-en-Provence, France, 10-11 March 2008; Gero, J.S., Ed.; 2008.

20. Daly, S.R.; Mosyjowski, E.A.; Seifert, C.M. Teaching creativity in engineering courses. J. Eng. Educ. 2014, 103, 417-449. [CrossRef]

21. Sarkar, P.; Chakrabarti, A. Assessing design creativity. Des. Stud. 2011, 32, 348-383. [CrossRef]

22. Shah, J.J.; Vargas-Hernandez, N.; Smith, S.M. Metrics for measuring ideation effectiveness. Des. Stud. 2003, 24, 111-134. [CrossRef]

23. Fiorineschi, L.; Frillici, F.S.; Rotini, F. Impact of Missing Attributes on A Posteriori Novelty Assessments. Res. Eng. Des. 2020, 31, 221-234. [CrossRef]

24. Oman, S.K.; Tumer, I.Y.; Wood, K.; Seepersad, C. A comparison of creativity and innovation metrics and sample validation through in-class design projects. Res. Eng. Des. 2013, 24, 65-92. [CrossRef]

25. Genco, N.; Hölttä-Otto, K.; Seepersad, C.C. An experimental investigation of the innovation capabilities of undergraduate engineering students. J. Eng. Educ. 2012, 101, 60-81. [CrossRef]

26. Robinson, M.A.; Sparrow, P.R.; Clegg, C.; Birdi, K. Design engineering competencies: Future requirements and predicted changes in the forthcoming decade. Des. Stud. 2005, 26, 123-153. [CrossRef]

27. Amabile, T.M. The Social Psychology of Creativity; Kidd, R.F., Ed.; Springer: New York, NY, USA, 1983; ISBN 9781461255352.

28. Jansson, D.G.; Smith, S.M. Design fixation. Des. Stud. 1991, 12, 3-11. [CrossRef]

29. Crilly, N. Fixation and creativity in concept development: The attitudes and practices of expert designers. Des. Stud. 2015, 38, 54-91. [CrossRef]

30. Youmans, R.J.; Arciszewski, T. Design Fixation: A Cloak of Many Colors. In Design Computing and Cognition 12; Gero, J.S., Ed.; Springer: Dordrecht, The Netherlands, 2014.

31. Purcell, A.T.; Gero, J.S. Design and other types of fixation. Des. Stud. 1996, 17, 363-383. [CrossRef] 
32. Tsenn, J.; Atilola, O.; McAdams, D.A.; Linsey, J.S. The effects of time and incubation on design concept generation. Des. Stud. 2014, 35, 500-526. [CrossRef]

33. Goldschmidt, G.; Sever, A.L. Inspiring design ideas with texts. Des. Stud. 2011, 32, 139-155. [CrossRef]

34. Atilola, O.; Linsey, J. Representing analogies to influence fixation and creativity: A study comparing computer-aided design, photographs, and sketches. Artif. Intell. Eng. Des. Anal. Manuf. 2015, 29, 161-171. [CrossRef]

35. Atilola, O.; Tomko, M.; Linsey, J.S. The effects of representation on idea generation and design fixation: A study comparing sketches and function trees. Des. Stud. 2015, 42, 110-136. [CrossRef]

36. Agogué, M.; Kazakçi, A.; Hatchuel, A.; Le Masson, P.; Weil, B.; Poirel, N.; Cassotti, M. The impact of type of examples on originality: Explaining fixation and stimulation effects. J. Creat. Behav. 2014, 48, 1-12. [CrossRef]

37. Cascini, G.; Fiorineschi, L.; Rotini, F. Impact of Design Representations on Creativity of Design Outcomes. J. Integr. Des. Process Sci. 2019, 1-30, in press. [CrossRef]

38. Peeters, J.; Verhaegen, P.A.; Vandevenne, D.; Duflou, J.R. Refined Metrics for Measuring Novelty in Ideation. In Proceedings of the Proceedings of IDMME-Virtual Concept 2010, Bordeaux, France, 20-22 October 2010; pp. 1-4.

39. Nelson, B.A.; Wilson, J.O.; Rosen, D.; Yen, J. Refined metrics for measuring ideation effectiveness. Des. Stud. 2009, 30, 737-743. [CrossRef]

40. Pahl, G.; Beitz, W.; Feldhusen, J.; Grote, K.H. Engineering Design, 3rd ed.; Springer: London, UK, 2007; ISBN 9781846283185.

41. Altshuller, G.S. Creativity as an Exact Science; Gordon and Breach Science: Amsterdam, The Netherlands, 1984; ISBN 0677212305.

42. Shai, O.; Reich, Y. Infused design. I. Theory. Res. Eng. Des. 2004, 15, 93-107. [CrossRef]

43. Kroll, E.; Weisbrod, G. Testing and evaluating the applicability and effectiveness of the new idea-configuration-evaluation (ICE) method of conceptual design. Res. Eng. Des. 2020. [CrossRef]

44. Fiorineschi, L. Abstraction framework to support students in learning creative conceptual design. J. Eng. Des. Technol. 2018, 16, 616-636. [CrossRef]

45. Fu, K.; Murphy, J.; Yang, M.; Otto, K.; Jensen, D.; Wood, K. Design-by-analogy: Experimental evaluation of a functional analogy search methodology for concept generation improvement. Res. Eng. Des. 2014, 26, 77-95. [CrossRef]

46. Eder, W.E. Design Modeling-A Design Science Approach (and Why Does Industry Not Use It?). J. Eng. Des. 1998, 9, 355-371. [CrossRef]

47. Guertler, M.R. How to Design Methods for Application-Empirical Insights from Industry. In Proceedings of the International Design Conference-Design 2018, Dubrovnik, Croatia, 21-24 May 2018; pp. 1161-1172.

48. Fiorineschi, L.; Frillici, F.S.; Rotini, F. Teaching and Learning Design Methods: Facing the Related Issues with TRIZ. In Proceedings of the Design Society: International Conference on Engineering Design, Dubrovnik, Croatia, 21-24 May 2019; pp. 589-598.

49. Reich, Y. The coronavirus pandemic: How can design help? Res. Eng. Des. 2020. [CrossRef]

50. Hubka, V.; Eder, W.E. Theory of Technical Systems: A Total Concept Theory for Engineering Design; Springer: Berlin, Germany, 1988; ISBN 9788578110796.

51. Eder, W.E.; Hosnedl, S. Design Engineering—A Manual for Enhanced Creativity, 1st ed.; CRC Press: Boca Raton, FL, USA, 2008.

52. Ulrich, K.T.; Eppinger, S.D. Product Design and Development, 5th ed.; Mc Graw Hill Irwin: New York, NY, USA, 2012; ISBN 9780073404776.

53. Ullman, D.G. The Mechanical Design Process, 4th ed.; Mc Graw HIll: New York, NY, USA, 2010; ISBN 978-0-07-297574-1.

54. Pugh, S. Total Design. Integrated Methods for Succesfull Product Engineering; Addison Wesley Publishing Company: Reading, MA, USA, 1991.

55. Tomiyama, T.; Gu, P.; Jin, Y.; Lutters, D.; Kind, C.; Kimura, F. Design methodologies: Industrial and educational applications. CIRP Ann. 2009, 58, 543-565. [CrossRef]

56. Kroll, E. Design theory and conceptual design: Contrasting functional decomposition and morphology with parameter analysis. Res. Eng. Des. 2013, 165-183. [CrossRef]

57. Chakrabarti, A.; Bligh, T.P. A scheme for functional reasoning in conceptual design. Des. Stud. 2001, 22, 493-517. [CrossRef] 
58. Fiorineschi, L.; Rotini, F. Unveiling the Multiple and Complex Faces of Fidelity. In Proceedings of the Design Society: International Conference on Engineering Design, Delft, The Netherlands, 5-8 August 2019; pp. 1723-1732.

59. McCurdy, M.; Connors, C.; Pyrzak, G.; Kanefsky, B.; Vera, A.; Field, M. Breaking the Fidelity Barrier: An Examination of our Current Characterization of Prototypes and an Example of a Mixed-Fidelity Success. In Proceedings of the SIGCHI Conference on Human Factors in Computing Systems, Montréal, QC, Canada, 22-27 April 2006; pp. 1233-1242.

60. Elverum, C.W.; Welo, T.; Tronvoll, S. Prototyping in new product development: Strategy considerations. Procedia CIRP 2016, 50, 117-122. [CrossRef]

61. Fiorineschi, L.; Rotini, F.; Rissone, P. A new conceptual design approach for overcoming the flaws of functional decomposition and morphology. J. Eng. Des. 2016, 27, 438-468. [CrossRef]

62. Christophe, F.; Bernard, A.; Coatanéa, É. RFBS: A model for knowledge representation of conceptual design. CIRP Ann. -Manuf. Technol. 2010, 59, 155-158. [CrossRef]

63. Gero, J.S.; Kanessegiesser, U. The situated function-behaviour-structure framework. Des. Stud. 2004, 25, 373-391. [CrossRef]

64. Srinivasan, V.; Chakrabarti, A. SAPPHIRE-An Approach to Analysos and Synthesis. In Proceedings of the International Conference on Engineering Design-ICED’09, Palo Alto, CA, USA, 24-27 August 2009; pp. 417-428.

65. Zwicky, F. Discovery, Invention, Research-Through the Morphological Approach.; Macmillan Publisher: New York, NY, USA, 1969.

66. Boden, M.A. What is creativity? In Dimensions of Creativity; MIT Press: Cambridge, MA, USA, 1994; pp. 75-117.

67. Jagtap, S. Design creativity: Refined method for novelty assessment. Int. J. Des. Creat. Innov. 2019, 7, 99-115. [CrossRef]

68. Fiorineschi, L.; Frillici, F.S.; Rotini, F. Orienting Through the Variants of the Shah A-Posteriori Novelty Metric. In Proceedings of the Design Society: International Conference on Engineering Design, Delft, The Netherlands, 5-8 August 2019; pp. 2317-2326.

69. Fiorineschi, L.; Rotini, F. A-Posteriori Novelty Metrics Based on Idea Decomposition. Int. J. Des. Sci. Technol. 2019, 23, 187-209.

70. Heller, J.E.; Schmid, A.; Löwer, M.; Feldhusen, J. The Dilemma of Morphological Analysis in Product Concept Synthesis-New Approaches for Industry and Academia. In Proceedings of the International Conference on Engineering Design-DESIGN 2014, Dubrovnik, Croatia,, 19-22 May 2014; pp. 201-210.

71. Fiorineschi, L. COVID-19 Ventilators: Schematic Representation. Available online: https://data.mendeley. com/datasets/jkvz7jrwny/2 (accessed on 1 July 2020).

72. Viswanathan, V.K.; Linsey, J.S. Role of Sunk Cost in Engineering Idea Generation: An Experimental Investigation. J. Mech. Des. 2018, 135, 121002. [CrossRef]

73. Shah, J.J.; Kulkarni, S.V.; Vargas-Hernandez, N. Evaluation of Idea Generation Methods for Conceptual Design: Effectiveness Metrics and Design. J. Mech. Des. 2000, 122, 377-384. [CrossRef]

74. Hennessey, B.A.; Amabile, T.M.; Mueller, J.S. Consensual Assessment, 2nd ed.; Academic Press: San Diego, CA, USA, 2011; Volume 1.

75. Gero, J.; Yu, R.; Wells, J. The effect of design education on creative design cognition of high school students. Int. J. Des. Creat. Innov. 2019, 7, 196-212. [CrossRef]

76. Saliminamin, S.; Becattini, N.; Cascini, G. Sources of creativity stimulation for designing the next generation of technical systems: Correlations with R\&D designers' performance. Res. Eng. Des. 2019, 30, 133-153. [CrossRef]

77. Fiorineschi, L.; Becattini, N.; Borgianni, Y. Testing a New Structured Tool for Supporting Requirements ' Formulation and Decomposition. Appl. Sci. 2020, 10, 3259. [CrossRef]

78. Roozenburg, N.F.M.; Eekels, J. Product Design: Fundamentals and Methods; John Wiley and Sons, Inc.: Hoboken, NJ, USA, 1991.

79. Dick, J.; Ryan, M.; Wheatcraft, L.; Zinni, R.; Baksa, K.; Fernandez, J.L.; Smith, G.R.; Unger, C. Guide to Writing Requirements; International Council on Systems Engineering: San Diego, CA, USA, 2012. 
80. Fanmuy, G.; Foughali, G. A survey on industrial practices in requirements engineering. In Proceedings of the Annual International Symposium of the International Council on Systems Engineering, INCOSE 2012 and the 8th Biennial European Systems Engineering Conference 2012, EuSEC 2012, Rome, Italy, 9-12 July 2012; International Council on Systems Engineering (INCOSE): San Diego, CA, USA, 2012; pp. 1112-1131.

81. Cropley, D.; Cropley, A. Recognizing and fostering creativity in technological design education. Int. J. Technol. Des. Educ. 2010, 20, 345-358. [CrossRef]

82. Hill, A.M. Problem Solving in Real-Life Contexts: An Alternative for Design in Technology Education. Int. J. Technol. Des. Educ. 1998, 8, 203-220. [CrossRef]

(C) 2020 by the authors. Licensee MDPI, Basel, Switzerland. This article is an open access article distributed under the terms and conditions of the Creative Commons Attribution (CC BY) license (http://creativecommons.org/licenses/by/4.0/). 